\title{
Effects of focal mild hypothermia on thrombin-induced brain edema formation and the expression of protease activated receptor-1, matrix metalloproteinase- 9 and aquaporin 4 in rats
}

\author{
DAPENG GAO ${ }^{1}$, FEIFAN DING ${ }^{1}$, GONGWEN LEI $^{1}$, GUOHUI LUAN $^{1}$, SHIBAO ZHANG $^{1}$, \\ KESEN LI ${ }^{2}$, DESHENG WANG ${ }^{1}$, LIMING ZHANG ${ }^{1}$ and DAWEI DAI ${ }^{1}$ \\ ${ }^{1}$ Department of Neurology, First Affiliated Hospital of Harbin Medical University, Harbin, Heilongjiang 150001; \\ ${ }^{2}$ Department of Neurology, Affiliated Hospital of Guangdong Medical College, Zhanjiang, Guangdong 524001, P.R. China
}

Received February 11, 2014; Accepted November 12, 2014

DOI: $10.3892 / \mathrm{mmr} .2014 .3111$

\begin{abstract}
Hypothermia is an effective neuroprotective treatment for brain injury caused by intracerebral hemorrhage ( $\mathrm{ICH})$. It is reported to reduce brain edema and neuronal cell death. Thrombin, a coagulation protease released from blood clots, is critical in brain edema formation following ICH. Protease activated receptor-1 (PAR-1), matrix metalloproteinase-9 (MMP-9) and aquaporin 4 (AQP4) are edema-associated mediators that have been implicated in $\mathrm{ICH}$ pathology. In the present study, thrombin was used to induce brain edema in adult male Sprague-Dawley rats. Differences between a focal mild hypothermic group $\left(33 \pm 0.5^{\circ} \mathrm{C}\right)$ and a normothermic group $\left(37^{\circ} \mathrm{C}\right)$ were investigated. Following hypothermia, brain water content and blood-brain barrier (BBB) disruption was assessed at 6, 24 and $48 \mathrm{~h}$ and subsequently at 3,5 and 7 days. At the same time, the mRNA and protein expression of PAR-1, MMP-9 and AQP4 were also determined. It was identified that brain water content and $\mathrm{BBB}$ disruption increased at $6 \mathrm{~h}$ and reached a maximal level at $24 \mathrm{~h}$ in the normothermic group. The mRNA and protein expression levels of PAR-1, MMP-9 and AQP4 started to increase at $24 \mathrm{~h}$ and reached a maximal level at $48 \mathrm{~h}$. Focal mild hypothermia tended to significantly reduce brain water content, BBB disruption and PAR-1, MMP-9 and AQP expression at 24 and $48 \mathrm{~h}$. The present data suggest that focal mild hypothermia is an effective treatment for edema formation
\end{abstract}

Correspondence to: Dr Liming Zhang or Dr Dawei Dai, Department of Neurology, First Affiliated Hospital of Harbin Medical University, 23 Youzheng Street, Nangang, Harbin, Heilongjiang, P.R. China

E-mail: zhangliminghlj@163.com

E-mail: ddwdlw@163.com

Key words: thrombin, intracerebral hemorrhage, aquaporin 4, focal mild hypothermia, protease activated receptor-1, matrix metalloproteinase-9 through moderation of the mRNA and protein expression of PAR-1, MMP-9 and AQP4.

\section{Introduction}

Intracerebral hemorrhage ( $\mathrm{ICH})$, a common and devastating disorder, accounts for $10-20 \%$ of all strokes (1) and causes brain edema and neuronal cell death. The rapid release of blood into the parenchyma results in limited hematoma, which causes blood-brain barrier (BBB) disruption, brain edema and inflammation. Secondary injury occurs resulting from the toxic effects of blood components, including thrombin (2) and erythrocyte rupture (3).

Thrombin, a serine protease, is an important component in the process of blood coagulation. The quantity of thrombin in the blood significantly exceeds the requirement of coagulation (4). The excess thrombin released from a hematoma or blood clot affects the microenvironment surrounding astrocytes and microglia (5) via activation of protease activated receptor-1 (PAR-1) (6). Matrix metalloproteinases (MMPs) are a family of zinc-dependent endopeptidase enzymes, which may cause degradation of extracellular matrix proteins and lead to an increase in BBB permeability and brain edema. Among the MMPs, MMP-9 is a major contributor to the disruption of the major components of the basal lamina surrounding cerebral blood vessels (7). Aquaporin 4 (AQP4), a member of the aquaporin family of water-selective transporting proteins, is important in cerebral water balance (8). Studies have demonstrated that increases in MMP-9 and AQP4 expression are associated with thrombin-induced disruption of the BBB and brain edema $(9,10)$.

Hypothermia has been established to exert neuroprotective properties in the acute phase following $\mathrm{ICH}(9,10)$. It may effectively relieve brain edema (11) and the disruption of the BBB (12) caused by thrombin and it reduces the accumulation of excitatory amino acids and free radicals $(13,14)$. Therefore, it is expected that reducing brain temperature may limit cell death, thereby improving recovery. However, this mechanism has not at present been clearly demonstrated.

To gain an improved understanding of the effects of hypothermia on thrombin-induced edema and the expression 
of PAR-1, MMP-9 and AQP4, a time course was established for their comparison. The current study aimed to elucidate whether hypothermic treatment is practical and effective in intracerebral hemorrhage in rats.

\section{Materials and methods}

Animal preparation and experimental groups. Adult male Sprague-Dawley rats ( $\mathrm{n}=360$; weight, 250-300 g) were used throughout the study. Animals were treated in accordance with the guidelines set by The Chinese Council for the Care and Use of Laboratory Animals and were approved by the Institutional Animal Care and Use Committee at the Harbin Medical University (Harbin, China). Rats were allowed free access to food and water and were housed with a $12 \mathrm{~h} / 12 \mathrm{~h}$ light/dark cycle. No mortality or signs of illness observed in the experimental animals.

The rats were anesthetized with chloral hydrate $(0.3 \mathrm{~g} / \mathrm{kg}$ body weight, intraperitoneally; Sigma-Aldrich, St. Louis, MO, USA) prior to aseptic surgery as previously described (15). Briefly, animals were placed in a stereotaxic frame (Bilaney Consultants GmbH, Düsseldorf, Germany). A midline scalp incision was made and a hole was drilled in the left side of the skull $(0.2 \mathrm{~mm}$ anterior, $3.0 \mathrm{~mm}$ lateral and $5.0 \mathrm{~mm}$ ventral, with respect to bregma); a total of $50 \mu 1$ thrombin $(10 \mathrm{U} / \mathrm{ml}$; Sigma-Aldrich) was injected into the right caudate nucleus (rats in the sham group received an injection of $50 \mu \mathrm{l}$ saline only). The syringe was subsequently removed slowly. The hole in the skull was sealed with bone wax (Shanghai Sanyou Medical Instrument Co., Ltd.,Shanghai,China) and the scalp was sutured. Body temperature was maintained at $37^{\circ} \mathrm{C}$ during surgery with the use of a feedback-controlled heating pad. Rats were randomly assigned to three groups: The normothermia (NT) group, the hypothermia (HT) group and the sham group. Rats in the NT and HT groups were euthanized using an overdose $(0.6 \mathrm{~g} / \mathrm{kg})$ of chloral hydrate at $6,24,48 \mathrm{~h}$ or 3,5 or 7 days after surgery ( $\mathrm{n}=6$ for each time point). Rats in the sham group $(n=6)$ were euthanized at $24 \mathrm{~h}$ after the infusion of saline.

Focal mild hypothermia. The rats in the HT group were cooled immediately following surgery with a hypothermia instrument (Patent no. ZL98236936.0; Harbin Institute of Technology, Harbin, China) following the thrombin injection as previously described (16). Briefly, following the injection of thrombin, the heads of the rats were fixed on the metallic plate of the hypothermia instrument, which reduced the cranial temperature to $33 \pm 0.5^{\circ} \mathrm{C}$; hypothermia was applied for $4 \mathrm{~h}$ from when the target temperature was reached. During the treatment of hypothermia, the temperature probes of the SL-4 temperature sensor (Tongji Medical University, Wuhan, China) were inserted into the ipsilateral and contralateral basal ganglia and rectum to monitor cranial and core temperatures. A heating pad was also used to maintain the core temperature at $\sim 37^{\circ} \mathrm{C}$. Rats rewarmed spontaneously following hypothermia and were allowed free access to food and water. Rats in the NT group were subject to the same conditions as the HT group with the exception of the hypothermia treatment.

Western blot analysis. The brains were removed and dissected rapidly and the striatal tissues $(3 \times 3 \times 3 \mathrm{~mm}, \sim 100 \mathrm{mg})$ were collected. Western blot analysis was performed as previously described (17). Briefly, brain tissues were ground in liquid nitrogen and proteins were extracted using a Tissue Protein Extraction Reagent (Boster Biological Technology, Inc., Wuhan, China). The protein concentration was detected using a bicinchoninic acid protein assay kit (Santa Cruz Biotechnology, Inc., Lake Placid, NY, USA). Subsequently, proteins were separated by sodium dodecyl sulfate-polyacrylamide gel electrophoresis and transferred onto a polyvinylidene fluoride membrane (Santa Cruz Biotechnology, Inc.). Following blocking with $5 \%$ bovine serum albumin for $2 \mathrm{~h}$, membranes were subsequently incubated with mouse monoclonal thrombin R (ATAP2; sc-13503; 1:1,000; Santa Cruz Biotechnology, Inc.), mouse monoclonal anti-AQP4 (C-19; sc-9888; 1:1,000; Santa Cruz Biotechnology, Inc.) and goat polyclonal anti-MMP-9 (C-20; sc-6840; 1:1,000; Santa Cruz Biotechnology, Inc.) overnight at $4^{\circ} \mathrm{C}$. The following day, the membrane was washed with Tris-buffered saline with Tween $^{\circledR}$ (TBS-T; 3x10 min) and subsequently incubated with horseradish peroxidase-conjugated goat anti-mouse (BA1051) or rabbit anti-goat (BA1060) secondary antibodies (1:500; Boster Biological Technology, Inc.) at room temperature for $2 \mathrm{~h}$. The membrane was washed again with TBS-T (3x10 min) and the results were visualized using electrochemiluminescence and luminol reagent (sc-2048; 1:1 ratio of solutions A and B; Santa Cruz Biotechnology, Inc.).

Reverse transcription-quantitative polymerase chain reaction (RT-qPCR). RT-qPCR was used to determine mRNA expression levels of PAR-1, MMP-9 and AQP4 in the brain. Total RNA was extracted from the frozen tissue samples with TRIzol ${ }^{\circledR}$ reagent (Invitrogen Life Technologies, Carlsbad, CA, USA) (17) at each time point following thrombin injection. PCR procedures were performed as follows: Each reaction volume was $25 \mu \mathrm{l}$. PCR was performed at $95^{\circ} \mathrm{C}$ for $2 \mathrm{~min}, 94^{\circ} \mathrm{C}$ for $1 \mathrm{~min}, 58^{\circ} \mathrm{C}$ for $45 \mathrm{sec}$, followed by 25 cycles of $74^{\circ} \mathrm{C}$ for $10 \mathrm{~min}$. The primer sequences were as follows: Forward: 5'-TGCGGTCCTTTGCTGTCTTC-3' and reverse: 5'-GTCTTCTGTCTCCACTTGGCT-3' for PAR-1; forward: 5'-TCCTCTACCTGGTCACACCC-3' and reverse: 5'-GTCTTCTGTCTCCACTTGGCT-3' for AQP4; forward: 5'-ACCTCCAACCTCACGGACA-3' and reverse: 5'-GTCTTCTGTCTCCACTTGGCT-3' for MMP-9; and

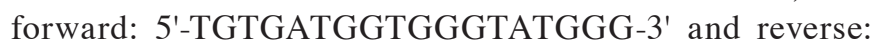
5'-TAGAAGCATTTGCGGTGC-3' for $\beta$-actin.

Determination of $B B B$ permeability. BBB permeability was evaluated using the Evans Blue dye method (EB) enabling the identification of extravasation (18). Briefly, EB (2\%, $4 \mathrm{ml} / \mathrm{kg})$ was injected intravenously and allowed to circulate for $2 \mathrm{~h}$. The brain was subsequently transcardially perfused with $200 \mathrm{ml}$ saline through the left ventricle until colorless liquid was obtained from the right atrium. Following decapitation, the brain was removed and $100 \mathrm{mg}$ of tissue surrounding the brain injury was dissected. For quantitative measurements, the brain samples were placed in $5 \mathrm{ml}$ formamide solution and incubated for $72 \mathrm{~h}$ at $37^{\circ} \mathrm{C}$. The optical density of the EB formamide solution was determined by spectrophotometry (Multiskan MK3; Thermo Fisher Scientific, Waltham, MA, USA) at $620 \mathrm{~nm}$ and the absorbance of the supernatant solution was measured according to the $\mathrm{EB} /$ formamide standard samples. The BBB permeability was expressed as EB/g of brain tissue. 
A

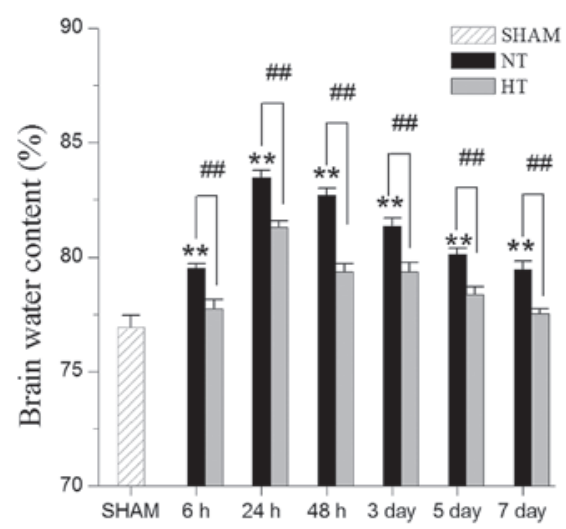

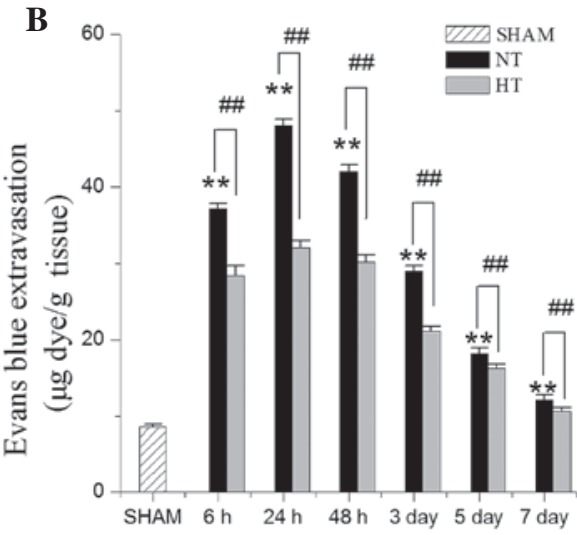

Figure 1. Effect of HT on brain water content and blood brain barrier permeability. (A) As determined by the dry-wet weight method, cerebral edema increased in the NT group compared with the sham group. Hypothermia decreased the edema. (B) Evans Blue extravasation was measured at each time point. Values are presented as the mean \pm standard deviation ( $\left(\mathrm{P}<0.05\right.$ and ${ }^{* *} \mathrm{P}<0.01$ vs. the sham group; ${ }^{*} \mathrm{P}<0.05$ and ${ }^{\# \#} \mathrm{P}<0.01$ vs. the NT group). NT, normothermia; HT, hypothermia.

A
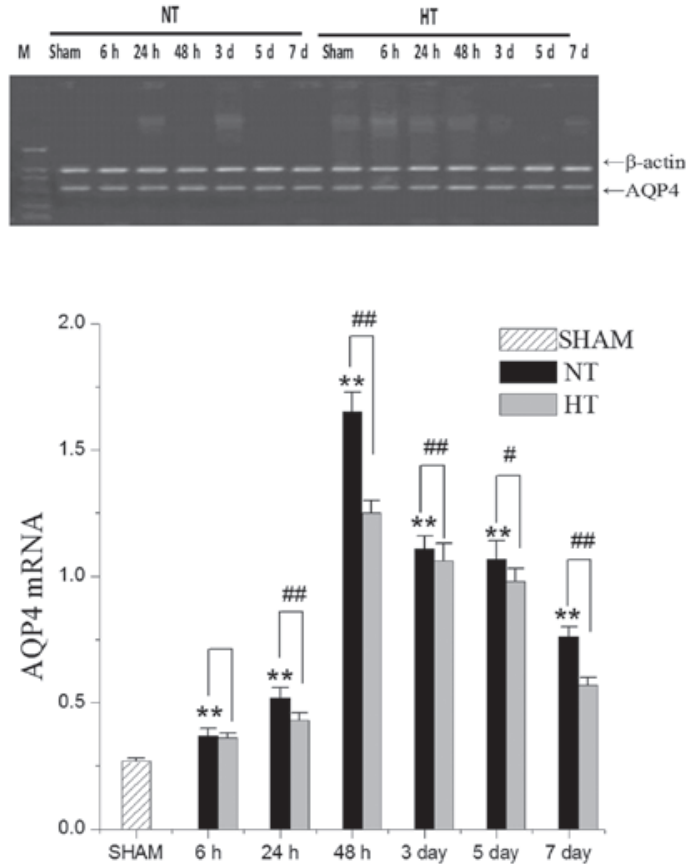

B
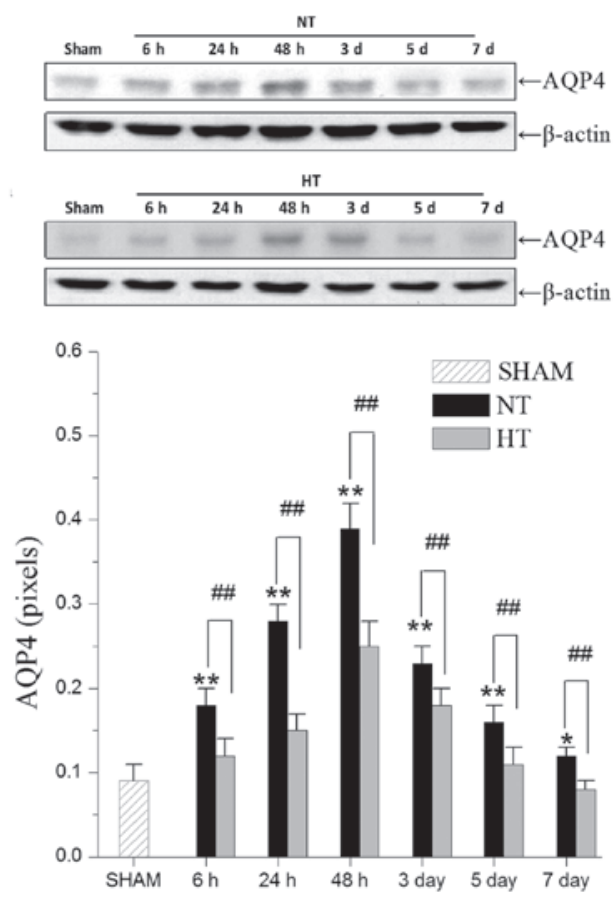

Figure 2. Hypothermia attenuated AQP4 expression in the HT group compared with the NT group. (A) Reverse transcription-quantitative polymerase chain reaction revealed AQP4 mRNA reached a peak level at $48 \mathrm{~h}$. The HT group had a significant reduction in AQP4 mRNA compared with the NT group at $48 \mathrm{~h}$. (B) Western blot analysis demonstrated AQP4 protein expression at each time point. Values are presented as the mean \pm standard deviation $(" \mathrm{P}<0.05$ and ${ }^{* *} \mathrm{P}<0.01$ vs. the sham group; ${ }^{\#} \mathrm{P}<0.05$ and ${ }^{\# \#} \mathrm{P}<0.01$ vs. the NT group). NT, normothermia; HT, hypothermia; AQP4, aquaporin 4.

Determination of brain water content. Brain water content was determined using the dry-wet weight method (19). Following decapitation, rat brain samples were immediately weighed on an electronic analytical balance (JA1003A Electronic Precision Balance; Changzhou Keyuan Balance Instrument Co., Ltd., Changzhou, China) to obtain the wet weight. The tissues were subsequently dried in an oven at $100^{\circ} \mathrm{C}$ for $24 \mathrm{~h}$ to obtain the dry weight. Brain water content was calculated as: Wet weight-dry weight)/wet weight x 100 .

Statistical analysis. Data are expressed as the mean \pm standard deviation. The analyses for multiple groups were performed using an analysis of variance followed by Tukey's honest significant difference post hoc test; independent two-sample t-tests were used to compare the means of the two groups at each time point. All data were analyzed with SPSS 17.0 statistical software (SPSS, Inc., Chicago, IL, USA). $\mathrm{P}<0.05$ was considered to indicate a statistically significant difference.

\section{Results}

Brain water content and BBB permeability. Following the injection of thrombin, the brain water content in the basal ganglia began to increase within $6 \mathrm{~h}$ in the NT group $(n=6)$ and reached a maximum at $24 \mathrm{~h}$. Furthermore, increased levels were maintained at $72 \mathrm{~h}$. The HT group exhibited a lower 

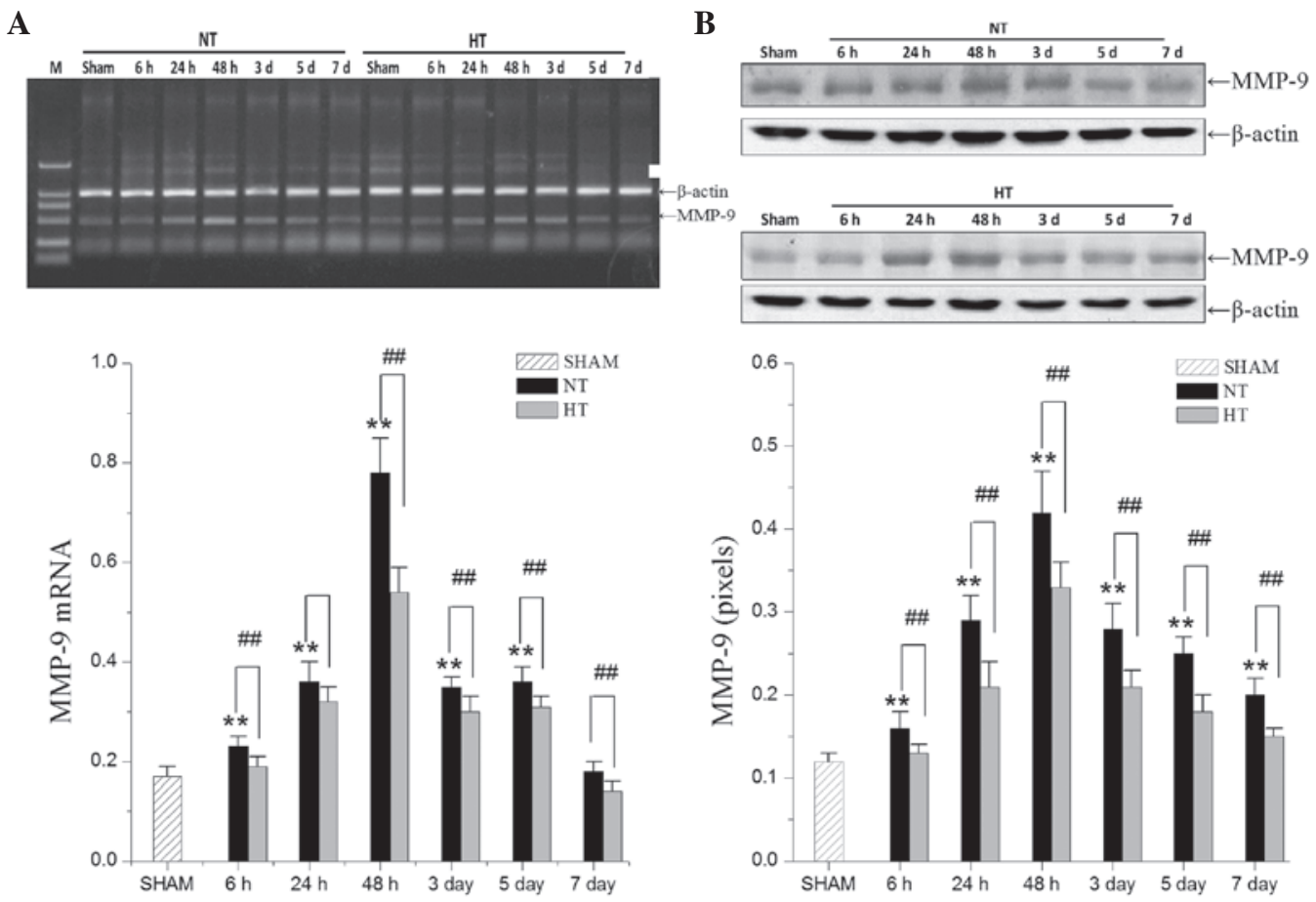

Figure 3. MMP-9 mRNA and protein expression surrounding the hematoma following the injection of thrombin. (A) Reverse transcription-quantitative polymerase chain reaction revealed MMP-9 increased in the NT group and decreased in the HT group. (B) Western blot analysis indicating the MMP-9 expression in the NT group and the HT group. Values are presented as the mean \pm standard deviation $\left({ }^{*} \mathrm{P}<0.05\right.$ and ${ }^{* * *} \mathrm{P}<0.01$ vs. the sham group; ${ }^{\#} \mathrm{P}<0.05$ and ${ }^{\# \#} \mathrm{P}<0.01 \mathrm{vs}$. the NT group). NT, normothermia; HT, hypothermia; MMP-9, matrix metalloproteinase-9.

A
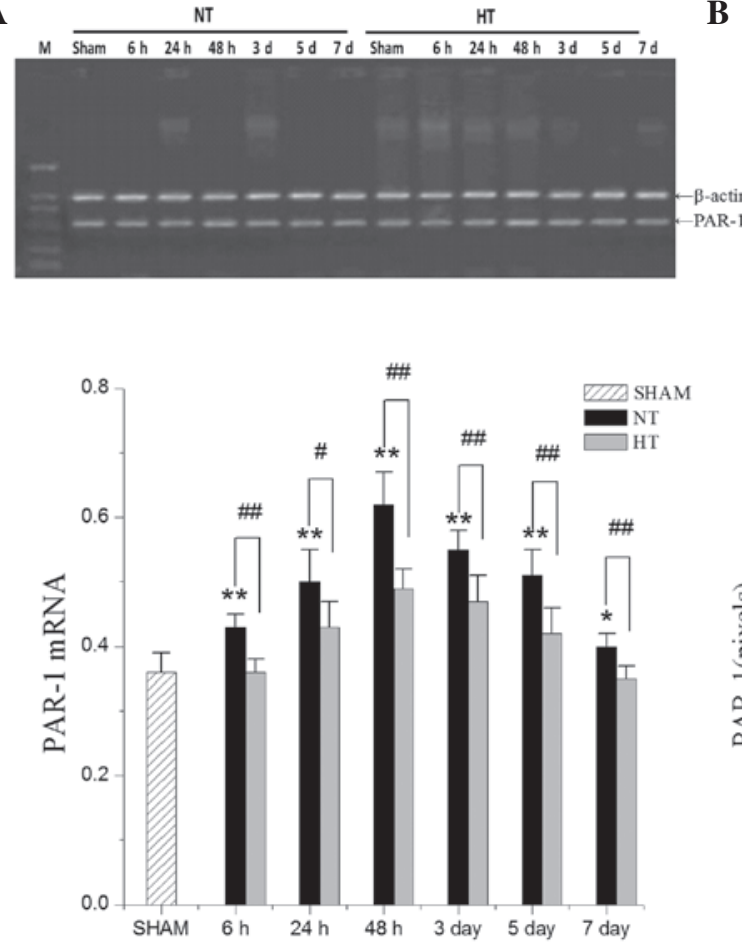

B
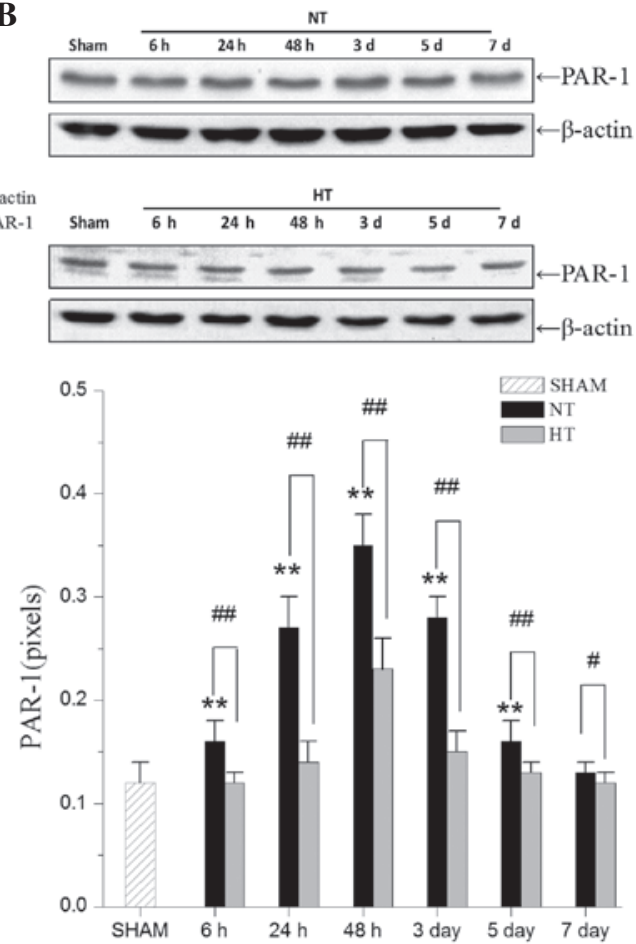

Figure 4. PAR-1 mRNA and protein expressed following thrombin injection in the rat brain. (A) Reverse transcription-quantitative polymerase chain reaction revealed that PAR-1 increased in the NT group and decreased in the HT group. (B) Western blot analysis indicating PAR-1 expression in the NT group and the HT group. Values are presented as the mean \pm standard deviation $\left({ }^{*} \mathrm{P}<0.05\right.$ and ${ }^{* *} \mathrm{P}<0.01$ vs. the sham group; ${ }^{*} \mathrm{P}<0.05$ and ${ }^{\# \#} \mathrm{P}<0.01$ vs. the $\mathrm{NT}$ group). $\mathrm{NT}$, normothermia; HT, hypothermia; PAR-1, protease activated receptor-1.

brain water content in the basal ganglia compared with the NT group $(\mathrm{P}<0.05)$. The brain water content began to decline at $48 \mathrm{~h}$ after thrombin injection (Fig. 1A).
The BBB permeability to EB, which is a protein-binding dye that binds to albumin and a marker of BBB extravasation, demonstrated a trend similar to the brain water content. A 
previous study identified that hypothermia did not alter the BBB permeability in normal tissue (11). The extent of EB extravasation observed in the damaged brain tissue increased rapidly within $6 \mathrm{~h}$ and reached a maximum at $24 \mathrm{~h}$. The level of EB extravasation was attenuated at $48 \mathrm{~h}$. Hypothermia significantly reduced the EB extravasation (Fig. 1B).

Effects of focal hypothermia on thrombin-induced AQP4 expression. To determine whether hypothermia affected AQP4, levels of AQP4 were measured at 6, 24, 48 and $72 \mathrm{~h}$ and 3, 5 and 7 days by RT-qPCR and western blot analysis (Fig. 2). AQP4 expression reached a peak at $48 \mathrm{~h}$. Compared with the NT group, in the HT group there was a significant decrease in AQP4 expression at each time point.

Effects of focal hypothermia on thrombin-induced MMP-9 expression. Using RT-qPCR and western blot analysis, the expression levels of MMP-9 in the HT group and the NT group were compared. MMP-9 mRNA and protein expression (Fig. 3) significantly increased at $24 \mathrm{~h}$ and peak levels were observed at $48 \mathrm{~h}$. Hypothermia led to a decreased expression of MMP-9.

Effects of focal hypothermia on thrombin-induced PAR-I expression. To investigate whether hypothermia decreased PAR-1 expression, RT-qPCR and western blot analysis was used to analyze the differences between the HT group and the NT group (Fig. 4). The data revealed that hypothermia in the HT group attenuated PAR-1 mRNA and protein expression compared with the NT group.

\section{Discussion}

Hypothermia is a neuroprotective strategy in ICH (20) and has been demonstrated to moderate perihematomal edema $(11,21)$. Edema formation, following ICH has a close association with thrombin (2); however, little is known of the time course of effects of mild focal hypothermia on thrombin-induced edema formation in rats. The principal aims of the present study were to examine the mechanisms underlying the neuroprotective effects of focal mild hypothermia following $\mathrm{ICH}$.

The results indicated that edema in the HT group significantly decreased within 24 and $72 \mathrm{~h}$ compared with the NT group following thrombin infusion. However, the mechanisms responsible for the edema induced by thrombin remain to be elucidated. Previous evidence has indicated that thrombin-induced vasogenic brain edema formation responds to the activation of PAR-1 and the disruption of the BBB $(22,23)$. In the present study, PAR-1 within the NT group increased within $6 \mathrm{~h}$ and reached a maximum level at $48 \mathrm{~h}$ after thrombin infusion. Treatment with focal mild hypothermia downregulated this level markedly, which indicated that focal mild hypothermia effected thrombin-PAR-1 signaling to reduce $\mathrm{BBB}$ permeability.

The present study identified that MMP-9 expression was correlated with the breakdown of BBB integrity (24). Furthermore, upregulation of MMP-9 expression in the perihematomal region following ICH has been reported in clinical patients (25) and rats (26). The present study demonstrated that MMP-9 expression in the NT group reached a maximal level at $48 \mathrm{~h}$ and remained increased at $72 \mathrm{~h}$ after thrombin infusion, which is consistent with previous findings $(19,27)$. Compared with the NT group, the HT group had downregulated the maximal level of MMP-9 at $48 \mathrm{~h}$. According to the present data and a previous study (16), the reduction of MMP-9 expression caused by mild focal hypothermia was responsible for moderating $\mathrm{BBB}$ disruption.

The effect of thrombin on AQP4 expression is inconclusive. A study has suggested that AQP4 expression is upregulated following ICH (28), whereas other evidence has demonstrated that thrombin inhibits AQP4 expression (29). The present study revealed that AQP4 expression in the NT group increased within $6 \mathrm{~h}$, reached a maximum level at $48 \mathrm{~h}$ and increased levels were maintained for 7 days. Therapy with focal mild hypothermia induced a robust reduction of AQP4 levels at $48 \mathrm{~h}$ and returned to approximately normal levels at 7 days in the HT group. These findings demonstrate that focal mild hypothermia was associated with a downregulation in AQP4 expression.

In conclusion, the present study has demonstrated that focal mild hypothermia may be neuroprotective and ameliorates the edema induced by thrombin, which disrupts the BBB through the activation of the PAR-1 pathway. In addition, focal mild hypothermia downregulates the expression of MMP-9 and AQP4, which are closely associated with brain edema. These findings provide evidence for using hypothermia in the treatment of ICH.

\section{Acknowledgements}

This study was supported by The Natural Sciences Foundation of Heilongjiang Province, China (grant no. QC2009C77).

\section{References}

1. Sacco S, Marini C, Toni D, Olivieri L and Carolei A: Incidence and 10-year survival of intracerebral hemorrhage in a population-based registry. Stroke 40: 394-399, 2009.

2. Lee KR, Colon GP, Betz AL, Keep RF, Kim S and Hoff JT: Edema from intracerebral hemorrhage: the role of thrombin. J Neurosurg 84: 91-96, 1996.

3. Xi G, Keep RF and Hoff JT: Erythrocytes and delayed brain edema formation following intracerebral hemorrhage in rats. J Neurosurg 89: 991-996, 1998.

4. Arand AG and Sawaya R: Intraoperative chemical hemostasis in neurosurgery. Neurosurgery 18: 223-233, 1986.

5. Noorbakhsh F, Vergnolle N, Hollenberg MD and Power C: Proteinase-activated receptors in the nervous system. Nat Rev Neurosci 4: 981-990, 2003.

6. Xue M, Hollenberg MD, Demchuk A and Yong VW: Relative importance of proteinase-activated receptor-1 versus matrix metalloproteinases in intracerebral hemorrhage-mediated neurotoxicity in mice. Stroke 40: 2199-2204, 2009.

7. Rosenberg GA: Matrix metalloproteinases in neuroinflammation. Glia 39: 279-291, 2002.

8. Zador Z, Stiver S, Wang V and Manley GT: Role of aquaporin-4 in cerebral edema and stroke. Handb Exp Pharmacol 190: 159-170, 2009.

9. Dietrich WD, Atkins CM and Bramlett HM: Protection in animal models of brain and spinal cord injury with mild to moderate hypothermia. J Neurotrauma 26: 301-312, 2009.

10. MacLellan CL, Clark DL, Silasi G and Colbourne F: Use of prolonged hypothermia to treat ischemic and hemorrhagic stroke. J Neurotrauma 26: 313-323, 2009.

11. Kawai N, Kawanishi M, Okauchi M and Nagao S: Effects of hypothermia on thrombin-induced brain edema formation. Brain Res 895: 50-58, 2001. 
12. Kawanishi M, Kawai N, Nakamura T, Luo C, Tamiya T and Nagao S: Effect of delayed mild brain hypothermia on edema formation after intracerebral hemorrhage in rats. J Stroke Cerebrovasc Dis 17: 187-195, 2008.

13. Busto R, Globus MY, Dietrich WD, et al: Effect of mild hypothermia on ischemia-induced release of neurotransmitters and free fatty acids in rat brain. Stroke 20: 904-910, 1989.

14. Globus MY, Alonso O, Dietrich WD, Busto R and Ginsberg MD: Glutamate release and free radical production following brain injury: effects of posttraumatic hypothermia. J Neurochem 65: 1704-1711, 1995

15. Fingas M, Clark DL and Colbourne F: The effects of selective brain hypothermia on intracerebral hemorrhage in rats. Exp Neurol 208: 277-284, 2007.

16. Zhao JK, Guan FL, Duan SR, et al: Effect of focal mild hypothermia on expression of MMP-9, TIMP-1, Tau- 1 and $\beta$-APP in rats with cerebral ischaemia/reperfusion injury. Brain Inj 27: 1190-1198, 2013

17. Wu H, Zhang Z, Li Y, et al: Time course of upregulation of inflammatory mediators in the hemorrhagic brain in rats: correlation with brain edema. Neurochem Int 57: 248-253, 2010.

18. Arican N, Kaya M, Kalayci R, Kucuk M, Cimen V and Elmas I: Effects of acute cold exposure on blood-brain barrier permeability in acute and chronic hyperglycemic rats. Forensic Sci Int 125: 137-141, 2002.

19. Song EC, Chu K, Jeong SW, et al: Hyperglycemia exacerbates brain edema and perihematomal cell death after intracerebral hemorrhage. Stroke 34: 2215-2220, 2003.

20. Jiang J, Yu M and Zhu C: Effect of long-term mild hypothermia therapy in patients with severe traumatic brain injury: 1-year follow-up review of 87 cases. J Neurosurg 93: 546-549, 2000.
21. Kollmar R, Staykov D, Dörfler A, Schellinger PD, Schwab $\mathrm{S}$ and Bardutzky J: Hypothermia reduces perihemorrhagic edema after intracerebral hemorrhage. Stroke 41: 1684-1689, 2010.

22. Xue M, Fan Y, Liu S, Zygun DA, Demchuk A and Yong VW: Contributions of multiple proteases to neurotoxicity in a mouse model of intracerebral haemorrhage. Brain 132: 26-36, 2009.

23. Xi G, Keep RF and Hoff JT: Mechanisms of brain injury after intracerebral haemorrhage. Lancet Neurol 5: 53-63, 2006.

24. Valable S, Montaner J, Bellail A, et al: VEGF-induced BBB permeability is associated with an MMP-9 activity increase in cerebral ischemia: both effects decreased by Ang-1. J Cereb Blood Flow Metab 25: 1491-1504, 2005.

25. Mun-Bryce S, Wilkerson A, Pacheco B, et al: Depressed cortical excitability and elevated matrix metalloproteinases in remote brain regions following intracerebral hemorrhage. Brain Res 1026: 227-234, 2004.

26. Wang J and Tsirka SE: Neuroprotection by inhibition of matrix metalloproteinases in a mouse model of intracerebral haemorrhage. Brain 128: 1622-1633, 2005.

27. Heo JH, Lucero J, Abumiya T, Koziol JA, Copeland BR and del Zoppo GJ: Matrix metalloproteinases increase very early during experimental focal cerebral ischemia. J Cereb Blood Flow Metab 19: 624-633, 1999.

28. Qing WG, Dong YQ, Ping TQ, et al: Brain edema after intracerebral hemorrhage in rats: the role of iron overload and aquaporin 4: Laboratory investigation. J Neurosurg 110: 462-468, 2009.

29. Tang Y, Cai D and Chen Y: Thrombin inhibits aquaporin 4 expression through protein kinase $\mathrm{C}$-dependent pathway in cultured astrocytes. J Mol Neurosci 31: 83-93, 2007. 